\title{
Commentary: Kappen S, Jürgens V, Freitag MH, Winter A. Attitudes Toward and Use of Prostate-Specific Antigen Testing Among Urologists and General Practitioners in Germany: A Survey
}

\author{
Kay-Patrick Braun ${ }^{1 *}$, Ingmar Wolff ${ }^{2}$, Steffen Lebentrau ${ }^{3}$ and Matthias May ${ }^{4}$ \\ ${ }^{1}$ Medizinisches Versorgungszentrum (MVZ) Dr. Braun GmbH, Cottbus, Germany, ${ }^{2}$ Department of Urology, University \\ Medicine Greifswald, Greifswald, Germany, ${ }^{3}$ Department of Urology, Werner Forssmann Clinic, Eberswalde, Germany, \\ ${ }^{4}$ Department of Urology, St. Elisabeth Hospital Straubing, Brothers of Mercy Hospital, Straubing, Germany
}

OPEN ACCESS

Edited by:

Wei Zhang,

Northwestern University,

United States

Reviewed by:

Chang Zeng,

Northwestern University,

United States

*Correspondence:

Kay-Patrick Braun

kay-p.braun@web.de

Specialty section:

This article was submitted to Cancer Epidemiology and Prevention, a section of the journal

Frontiers in Oncology

Received: 22 December 2021 Accepted: 03 January 2022 Published: 20 January 2022

Citation:

Braun K-P, Wolff I, Lebentrau S and May M (2022) Commentary: Kappen

$S$, Jürgens V, Freitag MH, Winter A. Attitudes Toward and Use of Prostate-

Specific Antigen Testing Among

Urologists and General Practitioners in

Germany: A Survey.

Front. Oncol. 12:841858.

doi: 10.3389/fonc.2022.841858
Keywords: prostatic neoplasms, early detection of cancer, prostate-specific antigen, physicians, healthcare surveys, attitudes, guideline adherence

\section{A Commentary on}

Attitudes Toward and Use of Prostate-Specific Antigen Testing Among Urologists and General Practitioners in Germany: A Survey

By Kappen S, Jürgens V, Freitag MH, Winter A. (2021) Front Oncol. 11:691197. doi: 10.3389/fonc.2021.691197

\section{INTRODUCTION}

The widespread use of Prostate-specific antigen (PSA)-based early detection (opportunistic PSAbased screening) of prostate cancer ( $\mathrm{PCa}$ ) since the beginning of this century has led to a marked reduction in cancer-specific mortality (CSM) and a simultaneous increase in incidence (1). However, screening also gave rise to an increasing detection of low-risk PCa without immediate need for treatment, resulting in controversial and critical discussions on the usefulness of opportunistic PSA-based screening which continue to the present day $(1,2)$. The US Preventive Task Force issued a recommendation against PSA screening in 2012, which was revised in 2017 as a consequence of the observed stage shift towards more advanced and metastatic stages resulting from the initial recommendation, in addition to study data supporting the evidence that PSA-based screening results in a significant reduction of $\operatorname{CSM}(1,3)$. Accordingly, it is now indisputable that PSA screening results in a decrease in CSM (by 35\% after 18 years of follow-up in the Göteborg arm of the European Randomized study of Screening for Prostate Cancer) and a lower incidence rate of metastatic disease stages, but it is also associated with a substantial risk of overdiagnosis $(1,4)$. Falsepositive findings and resulting eventual complications of prostate biopsy as well as subsequent overtreatment represent potential harm to patients invited for PSA-based screening (5). 
Worldwide, opportunistic PSA-based screening for PCa is performed by different professional groups potentially resulting in qualitative differences. In addition, the introduction of innovative strategies for PSA-based early PCa detection (riskadapted approach, integration of multiparametric magnetic resonance imaging) poses new challenges for physicians involved (1, 6, 7). Meritoriously, the working group around Sanny Kappen analyzed the attitudes of dominant professional groups responsible for opportunistic PSA-based screening in Germany (namely general practitioners (GPs) and urologists) using a comprehensive survey $(5,8-13)$. With great interest we noticed their recently published results which we would like to comment (11).

\section{DISCUSSION}

For colleagues from countries in which PSA-based early detection of PCa is at least in part provided by non-urology specialties, Kappen et al. present extremely important data (11). In Germany (as, for example, in the US), GPs perform a large part of opportunistic PSA-based screening (5, 8-13). Despite the selectivity of results (preconceiving the considerable bias resulting of GPs' response rate of only $6.1 \%$; query was performed in one German state only), the study by Kappen et al. provides answers to the following important questions: 1) What is the proportion of GPs performing PSA testing?, 2) What expectations do GPs associate with opportunistic PSA-based screening?, 3) Are current studies and guideline recommendations known and are they implemented in daily routine (especially concerning the target population of opportunistic PSA-based screening)?, 4) What quality of patient counselling precedes PSA determination?, and 5) What consequences are drawn from pathologically elevated PSA levels?
(Or: At which point in time do GPs schedule the integration of the urologist?).

Table 1 compares results on selected items from the current and another study by Kappen et al. with our own results obtained some years earlier within a German population of GPs and internists $(8,9,11,12)$. The willingness of non-urologists to perform PSA-based early detection of PCa in asymptomatic men has decreased over the years $(83.9 \%$ vs. $51.2 \%$ and $55.2 \%$, respectively, both tests with $\mathrm{p}<0.001$; Table 1 ). In this context, it seems noteworthy, that no significant difference was observed regarding this point between the first study by Kappen et al., which was smaller in terms of the number of GPs included, versus the current study by Kappen et al. comprising a higher number of cases $(51.2 \%$ vs. $55.2 \%, \mathrm{p}=0.711)$. Comparing their earlier 2016 study with our study from 2012, Kappen et al. found a significantly higher proportion of primary care physicians who did not perform PSA-based early detection of PCa at all in asymptomatic men $(\mathrm{p}<0.001$; Table 1$)$. However, a significantly higher rate of non-urologists considered the reduction of $\mathrm{PCa}$ specific mortality based on PSA screening as scientifically proven in the recent study by Kappen et al. compared to our data (20.8 vs. $12 \%, \mathrm{p}=0.030$ ). In contrast, we found this to be inconsistent with the reported higher screening readiness of non-urologists in their first study (12). In our opinion, it seems very important that Kappen et al. showed that patients with elevated PSA levels were significantly less likely to be directly referred to a urologist compared to our own results ( 53.1 vs. $68.6 \%, p=0.006$ ). This hesitation may result in a delay in PCa diagnosis, possibly hampering patients' prognosis.

A tiny downer in the otherwise excellent work of Kappen et al. is certainly that the authors solely opted for a purely descriptive analysis of their data (11). Considering multivariate analysis of our own survey study, it was striking that non-urologists who never attended topic-specific education by urological colleagues

TABLE 1 | Comparison of selected items from all studies conducted in Germany to survey non-urological physicians regarding their attitudes towards PSA-based early detection of PCa.

\begin{tabular}{|c|c|c|c|c|c|}
\hline Characterization of the studies & {$[11]$} & [12] & {$[8,9]$} & $p^{*}$ & $p^{* *}$ \\
\hline Year of the questionnaire study & 2019 & 2016 & 2012 & - & - \\
\hline Size of the primary study group contacted & 1579 & 172 & 600 & - & - \\
\hline Specialty of the non-urological physicians contacted & All GP & All GP & $\begin{array}{l}385 \text { GP and } 215 \\
\text { internists }\end{array}$ & - & - \\
\hline Returned questionnaires & 96 & 47 & 392 & - & - \\
\hline Size of the final evaluable study group & 96 & 41 & 392 & - & - \\
\hline Resulting response rate & $6.1 \%$ & $23.8 \%$ & $65.3 \%$ & - & - \\
\hline \multicolumn{6}{|l|}{ Presentation of selected items } \\
\hline Proportion of physicians who recommend PSA-based ED of PCa to asymptomatic patients & $\begin{array}{l}55.2 \% \\
(n=53)\end{array}$ & $\begin{array}{l}51.2 \% \\
(n=21)\end{array}$ & $83.9 \%(n=329)$ & $<.001$ & $<.001$ \\
\hline $\begin{array}{l}\text { Proportion of physicians who would not recommend PSA-based ED of PCa at all to } \\
\text { asymptomatic patients }\end{array}$ & n.a. & $\begin{array}{l}39.0 \% \\
(n=16)\end{array}$ & $10.2 \%(n=40)$ & n.a. & $<.001$ \\
\hline $\begin{array}{l}\text { Proportion of physicians who consider the reduction of PCa mortality by PSA screening to be } \\
\text { proven }\end{array}$ & $\begin{array}{l}20.8 \% \\
(n=20)\end{array}$ & n.a. & $12.0 \%(n=47)$ & .030 & n.a. \\
\hline $\begin{array}{l}\text { Proportion of physicians who primarily transfer patients with pathologically elevated PSA-levels to } \\
\text { urologists }\end{array}$ & $\begin{array}{l}53.1 \% \\
(n=51)\end{array}$ & $\begin{array}{l}68.3 \% \\
(n=28)\end{array}$ & $68.6 \%(n=269)$ & .006 & 1.000 \\
\hline
\end{tabular}

$p^{*}$, statistical difference calculated using the Chi² test (Fisher's exact test, two-sided) between the study of Kappen et al. (11) and our own study [8,9]; $p^{* *}$, statistical difference calculated using the Chi test (Fisher's exact test, two-sided) between the study of Kappen et al. (12) and our own study [8,9]; ED, early detection; GP, general practitioners; n.a., not available; PCa, prostate cancer; PSA, prostate-specific antigen. 
were almost 4 times more likely to perform opportunistic PSAbased screening of patients (compared with those who attended urological education events; OR 3.95, p=0.002) (9). Thus, a frequently observed phenomenon of medical practice seems to be confirmed: The more intensively one approaches the crucial aspects of a medical problem, the greater the humility in front of the complexity of the underlying issue gets.

Another remarkably interesting point in the work of Kappen et al. is the question of knowledge of the interdisciplinary S3 guideline led by the German Society of Urology (DGU) and the recommendations of the German Society of General Medicine (DEGAM) $(13,14)$. This fact is of utmost importance as statements differ considerably. While the DEGAM recommendation, which is three years older, advocates PSA-based early detection for PCa only for those patients who actively request it, the interdisciplinary $\mathrm{S} 3$ guideline allows physician's active initiative, provided that the patient is thoroughly informed about possible advantages and disadvantages of this PCa screening measure $(13,14)$. This could partly explain different attitudes of GPs and urologists towards PSA-based early detection.

We are currently conducting a study involving 150 GPs enabling us to analyze their attitude and individual approach

\section{REFERENCES}

1. Van Poppel H, Roobol MJ, Chapple CR, Catto JWF, N'Dow J, Sønksen J, et al. Prostate-Specific Antigen Testing as Part of a Risk-Adapted Early Detection Strategy for Prostate Cancer: European Association of Urology Position and Recommendations for 2021. Eur Urol (2021) 80(6):703-11. doi: 10.1016/ j.eururo.2021.07.024

2. Albertsen PC. PSA Testing, Cancer Treatment, and Prostate Cancer Mortality Reduction: What is the Mechanism? Urol Oncol (2021) 6:S1078-1439(21) 00369-0. doi: 10.1016/j.urolonc.2021.08.010

3. Leapman MS, Wang R, Park H, Yu JB, Sprenkle PC, Cooperberg MR, et al. Changes in Prostate-Specific Antigen Testing Relative to the Revised US Preventive Services Task Force Recommendation on Prostate Cancer Screening. JAMA Oncol (2021) 11:e215143. doi: 10.1001/jamaoncol.2021.5143

4. Hugosson J, Godtman RA, Carlsson SV, Aus G, Grenabo Bergdahl A, Lodding P, et al. Eighteen-Year Follow-Up of the Göteborg Randomized Population-Based Prostate Cancer Screening Trial: Effect of Sociodemographic Variables on Participation, Prostate Cancer Incidence and Mortality. Scand J Urol (2018) 52(1):27-37. doi: 10.1080/21681805. 2017.1411392

5. Paschen U, Sturtz S, Fleer D, Lampert U, Skoetz N, Dahm P. Assessment of Prostate-Specific Antigen Screening: An Evidence-Based Report by the German Institute for Quality and Efficiency in Health Care. BJU Int (2021). doi: 10.1111/bju.15444

6. Rannikko A, Leht M, Mirtti T, Kenttämies A, Tolonen T, Rinta-Kiikka I, et al. Population-Based Randomized Trial of Screening for Clinically Significant Prostate Cancer ProScreen: Pilot Study. BJU Int (2021). doi: 10.1111/ bju. 15683

7. Regmi SK, Sathianathen N, Stout TE, Konety BR. MRI/PET Imaging in Elevated PSA and Localized Prostate Cancer: A Narrative Review. Transl Androl Urol (2021) 10(7):3117-29. doi: 10.21037/tau-21-374

8. Lebentrau S, May M, Maurer O, Schostak M, Lehsnau M, Ecke T, et al. Rates of Prostate-Specific Antigen Testing for Early Detection of Prostate Cancer: A First Comparison of German Results With Current International Data. Urologe A (2014) 53(5):715-24. doi: 10.1007/s00120-014-3453-0

9. Gilfrich C, May M, Braun KP, Lebentrau S, Lehsnau M, Ecke T, et al. Evaluating the Use of Prostate-Specific Antigen as an Instrument for Early Detection of Prostate Cancer Beyond Urologists: Results of a Representative towards opportunistic PSA screening (KABOT study, Knowledge And Belief Over Time). Additionally, in this study, 50 consecutive male patients aged 45-70 years will receive a questionnaire from each participating GP. This allows, among other things, to analyze the type and extent of previous PSA testing based on patient's reports. Thus, after analysis of the KABOT study data, we should be able to answer the five questions above even more sufficiently.

\section{AUTHOR CONTRIBUTIONS}

All authors listed have made a substantial, direct, and intellectual contribution to the work and approved it for publication.

\section{FUNDING}

Open access publication was funded by the MVZ Dr. Braun GmbH.
Cross-Sectional Questionnaire Study of General Practitioners and Internal Specialists. Urol Int (2014) 93(2):160-9. doi: 10.1159/000356367

10. Braun KP, May M, Grassmel Y, Führer S, Hoschke B, Braun V. The General Practitioner's Part in the Initiation of Diagnostic Procedures in Prostate Cancer. Aktuelle Urol (2008) 39(2):141-6. doi: 10.1055/s-2007-993037

11. Kappen S, Jürgens V, Freitag MH, Winter A. Attitudes Toward and Use of Prostate-Specific Antigen Testing Among Urologists and General Practitioners in Germany: A Survey. Front Oncol (2021) 11:691197. doi: 10.3389/fonc.2021.691197

12. Kappen S, Jürgens V, Freitag MH, Winter A. Early Detection of Prostate Cancer Using Prostate-Specific Antigen Testing: An Empirical Evaluation Among General Practitioners and Urologists. Cancer Manag Res (2019) 11:3079-97. doi: 10.2147/CMAR.S193325

13. DEGAM Praxisempfehlung: Hausärztliche Beratung $\mathrm{Zu}$ PSA-Screening: (c) DEGAM 2018 DEGAM Leitlinien - Hilfen Für Eine Gute Medizin. Available at: http://www.degam-leitlinien.de (Accessed 20 December 2021).

14. Leitlinienprogramm Onkologie (Deutsche Krebsgesellschaft, Deutsche Krebshilfe, AWMF): S3-Leitlinie Prostatakarzinom, Langversion 6.0, 2021. Available at: http://www.leitlinienprogramm-onkologie.de/leitlinien/ prostatakarzinom/ (Accessed 20 December 2021). AWMF Registernummer: 043/022OL.

Conflict of Interest: The authors declare that the research was conducted in the absence of any commercial or financial relationships that could be construed as a potential conflict of interest.

Publisher's Note: All claims expressed in this article are solely those of the authors and do not necessarily represent those of their affiliated organizations, or those of the publisher, the editors and the reviewers. Any product that may be evaluated in this article, or claim that may be made by its manufacturer, is not guaranteed or endorsed by the publisher.

Copyright (c) 2022 Braun, Wolff, Lebentrau and May. This is an open-access article distributed under the terms of the Creative Commons Attribution License (CC BY). The use, distribution or reproduction in other forums is permitted, provided the original author(s) and the copyright owner(s) are credited and that the original publication in this journal is cited, in accordance with accepted academic practice. No use, distribution or reproduction is permitted which does not comply with these terms. 